\title{
Editorial der Schweizer Redaktion
}

\author{
Die Wirkungsgeschichte einer Idee \\ Nachdenken über die Analytische Psychologie
}

Die Redaktion Schweiz nimmt das 50jährige Jubiläum des C.G.-Jung-Instituts Zürich zum Anlass, um in zwei Ausgaben der Zeitschrift über die Analytische Psychologie nachzudenken und über die Wirkungsgeschichte des Jungschen Gedankens zu reflektieren.

Dabei kommen Kolleginnen und Kollegen zu Wort, die als Analytikerinnen und Analytiker in der Schweiz tätig sind, seit langem oder seit kurzem, und die an der Gestaltung der lehrenden und forschenden Wirklichkeit des Instituts mitwirken, ideell und institutionell.

Wenn wir mit einem - späten - Nachruf auf Marie-Louise von Franz beginnen, wollen wir damit eine persönliche Brücke zum Ursprung schlagen: das ein Leben füllende Nachdenken über Jung wurde zu einem lebendigen Weiterdenken seines Gedankens, so wie der Prozess der Individuation über den Tod hinausund weitergeht, wenn ein Mensch das Tal des Todes durchwandert hat: Gedanken von Frau Marie-Louise von Franz über das Unbewusste und den Tod. Alles ist Wandlung. So wandelt sich auch, über dem durchtragenden Fluss archetypischer Energie, die am Individuum und seiner sozialen Lebenswelt orientierte Analytische Psychologie, auch im notwendigen kritischen Nachdenken über Jung.

Die von unseren Kolleginnen und Kollegen Kathrin Asper, Verena Kast, Urs Mehlin, Martin Odermatt und Brigitte Spillmann vorgelegten Artikel sind im Rahmen der Jubiläumsveranstaltungen in einem Vorlesungszyklus am ETH-Zentrum in Zürich vorgetragen worden (12.-20. Mai 1998). Wir haben sie auf die beiden Hefte so verteilt, wie auch die übrigen Originalbeiträge zum Thema, dass eine gleiche Gewichtung erreicht wurde.

Die Eidgenössische Technische Hochschule war ein wesentlicher Ort der Verbreitung des Jungschen Gedankens, durch ihn selbst und durch seine Nach-

\footnotetext{
KARGER ( 1996 S. Karger AG, Basel

Fax + 41613061234

E-Mail karger@karger.ch

www. karger.com Accessible online at: 
folger. Und so kann es als eine symbolische Geste gesehen werden, dass wieder an diesem Ort über Tendenzen, Weiterentwicklungen und Wirkungsgeschichte der Analytischen Psychologie C.G. Jungs nachgedacht wurde und wird.

Die Artikel in ihrer - typisch Jungschen - thematischen Breite sollen widerspiegeln, was wissenschaftlich-empirisch, psychiatrisch-medizinisch, therapeutisch-heilend und spirituell-suchend als Impuls vom C.G.-Jung-Institut Zürich ausgeht auf der Suche nach dem aurum verum des prinzipiell unabschliessbaren Prozesses des Findens und Lassens.

Redaktion Schweiz Doris Lier

Kari Lothe

Arnold Bittlinger

William Carrard

Dirk Evers 